\title{
An experimental Investigation on Strength Properties of Concrete Containing FA and MS as Partial Replacement of Cement: An Overview
}

\author{
Harishav*, Mukesh Pandey**, Sohit Agrawal*** \\ *(PG Scholar, Department of Civil Engineering, ITM University, Gwalior-474001, India \\ ** (Professor and Head, Department of Civil Engineering, ITM University, Gwalior-474001, India \\ ***Assistant Professor, Department of Civil Engineering, ITM University, Gwalior-474001, India
}

\begin{abstract}
The report represents a proportion of the materials which can be used as replacing cement. Many previous studies have been done on various properties of concrete like durability, strength etc this is another interpretation from some former reports .this report will mainly focus on the properties of concrete like compressive, split tensile and flexural strength. With this evaluation a perfect combination of both these materials can be distinguished. Replacement to some part of cement (OPC) is done with FA and MS from last decades. If we go through these reports most of them came to a conclusion that these materials are hundred percent riskless and out of harm in any surrounding and under any observation. . These materials are best suitable for mix. The outcome of this analysis will set a better improvement step for conservation of cement to a limited extent along with its environment friendly and economical replacement.
\end{abstract}

Keywords: Cement replacement, Compressive strength, Flexural strength, FA, MS.

\section{INTRODUCTION}

Cement is a material whose production takes a lot of money, a lot of energy along with a lot of negative footprints for the society, environment etc. Chinese are the major producers of cement in the world followed by India (1). Urban developers and government planning of cities under the name smart cities in our country will give more rapid fulfillment for the cement demand. Almost 98 small and big towns are in the plan. 2025 will led the cement need to encounter about (2) 500-600 million tons per annum. For every individual $1000 \mathrm{~kg}$ of concrete (cement) is produced every year. Environment is being harmed with the production of this basic material every day. The power plants which mass produce cement is responsible for liberating flue and exhaust gases. (3) Dust, $\mathrm{co}_{2}$, oxides of $\mathrm{N}$ and $\mathrm{SO}_{2}$ are the prime troublemakers. Due to these major drawbacks replacement of cement is needful. Apart from FA and MS there are some more materials named as nano silica, ggbs, and rice husk etc

\section{Fly Ash}

Many countries have their main or alternative sources for power productions. These sources can be wind energy, solar energy and hydro energy. Unlike these countries majority of power produced in India is through the thermal stations. The process of power production in these stations carried through many operations like transporting the coal in its raw position to its breaking down then passing through precipitators undergoing hopers finally left over like dregs. These dregs are FA (FA). Because they are the tail ends they are considered as unintended results.

FA integrants can be:

$\begin{array}{rlr}\text { i. } & \mathrm{So}_{3}- & \begin{array}{l}\text { little amount } \\ \text { ii. }\end{array} \\ \text { iii. } & \begin{array}{l}\mathrm{Mgo}- \\ \text { little amount } \\ \text { percentage }\end{array} & \text { from } 1 \text { up to } 7 \\ \text { iv. } & \begin{array}{l}\text { carbon } \\ \text { alloys } 30 \text { percentage }\end{array} \\ \text { v. } & \begin{array}{l}\mathrm{Al}_{2} \mathrm{O} 3- \\ \text { percentage }\end{array} \\ \text { vi. } & \begin{array}{l}\mathrm{Sio}_{2} \\ \text { percentage }\end{array} & \text { from } 15 \text { up to } 30 \\ & \text { from } 30 \text { up to } 60\end{array}$

A succeeding and wide range of academic works makes FA a serviceable product from a by- product.

\section{Micro Silica}

MS can also be called as pyrogenic silica, fumed silica and silica fume. The shape of the substance cannot be sharply designated. Nature of this matter is polymorphic i.e. substance that occurs in diverse forms. It is also not a first product it is another secondary product. MS is assembled in operation of electric arc furnance in industries. People often cannot simplify silica fume with one fumed silica. The heterogeneity is its steps in making, action of 
making it practically workable in scenarios and fragments.

In the same way as FA a succeeding and wide range of academic works makes MS a serviceable product from a by- product.

The composition and texture makes MS very tiny in size. It has very less average size of grain particles. If we compare size of an average cement particle with an average MS particle size of the MS particle will be 100 times smaller than cement. According to verma ajay "These fumes is produced when quartz present in highly pure form is reduced with coal, coke or wooden chips during process of silicon metal production silica fume is obtained as byproduct".

Due to its low price, availability as a secondary product and environmental advantages it is being utilized widely. Negative segregation negative bleeding in concrete are some other utilities with less permeability's characteristics as tight bonding between the particles in the concrete do not allow anything to flow freely.

\section{LITERATURE REVIEW}

In the report by Hs jadhav (5) cement is replaced by the means of FA \& MS in concrete. Mixed proportion for which it was designed was M70. Curing period was divided into 7 days and 28 days for total 23 sets of specimens. he set the different specimens as $(0,2.5,5,7.5,10,12.5)$ percent of FA along with $(0,2.5,5,7.5,10,12.5)$ percent of MS. The outcomes with these different specimens when placed with normal concrete he discovered that a spacious value of 12.19 percent for compressive strength is detected. The coalition of (2.5percentFA along with 2.5percentMS) registered supreme values of 96.22 $\mathrm{N} / \mathrm{mm}^{2}$. Negative results were registered for the blunged effect

In the report by magudeaswaran (6) the experiment conducted was for M60 grade of concrete for curing period of 3,7,14 and 28 days. From the experiment he concluded that compressive strength when compared with control concrete with the combination of MS and FA was higher. Compressive strength increased by $13.9 \%$ when cement is replaced by $10 \% \mathrm{FA}$ and $5 \%$ silica fume. Combination of $15 \% \mathrm{FA}$ and $7.5 \%$ silica fume for split tensile strength was increased by $12.15 \%$. Also for flexural strength cement replaced by $15 \%$ FA and $7.5 \%$ silica fume led to increase in its strength by $16 \%$.

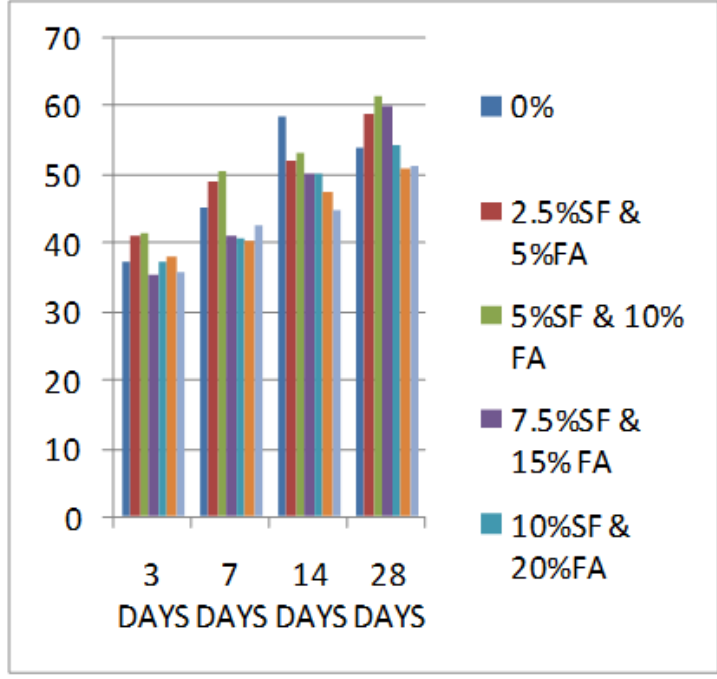

Fig no.6.1 compressive strength of SF \& FA replacement levels $\left(\mathrm{N} / \mathrm{mm}^{2}\right)$

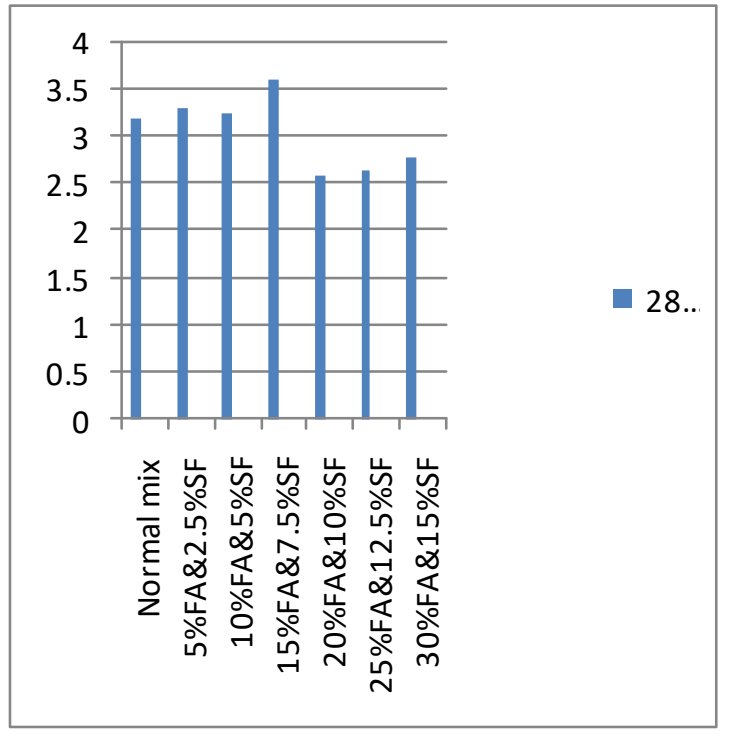

Fig no.6.2 split tensile strength of SF \& FA replacement levels $\left(\mathrm{n} / \mathrm{mm}^{2}\right)$

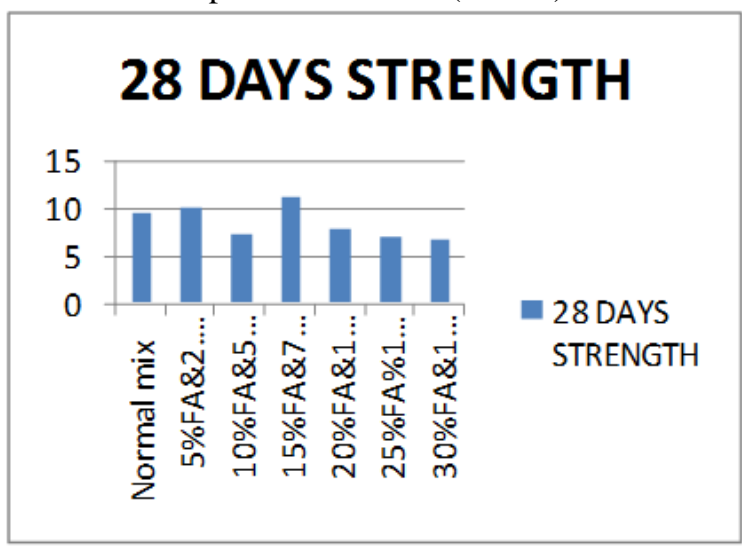

Fig no.6.3 flexural strength of SF\&FA replacement levels $\left(\mathrm{N} / \mathrm{mm}^{2}\right)$ 
Mudassir hussain pandit(7) did the experiment for a high density concrete using FA, MS and recycled aggregate for the strength properties like compressive strength and split tensile test for thirteen different mixes. The aggregates replaced were the coarse aggregates for M25 grade for 28 days curing period. The focus was to utilize used aggregates from wreck concrete and make a stiffed concrete with reduced number of pores. He concluded that both the pozzolanic materials along with recycled aggregates caused increase in the strength of concrete for more than $17 \%$. Permeability of concrete is reduced because of MS, FA and recycled concrete aggregates. $\mathrm{He}$ also concluded that partial replacement of cement can be done safely up to $15 \%$ replacement to get high strength.

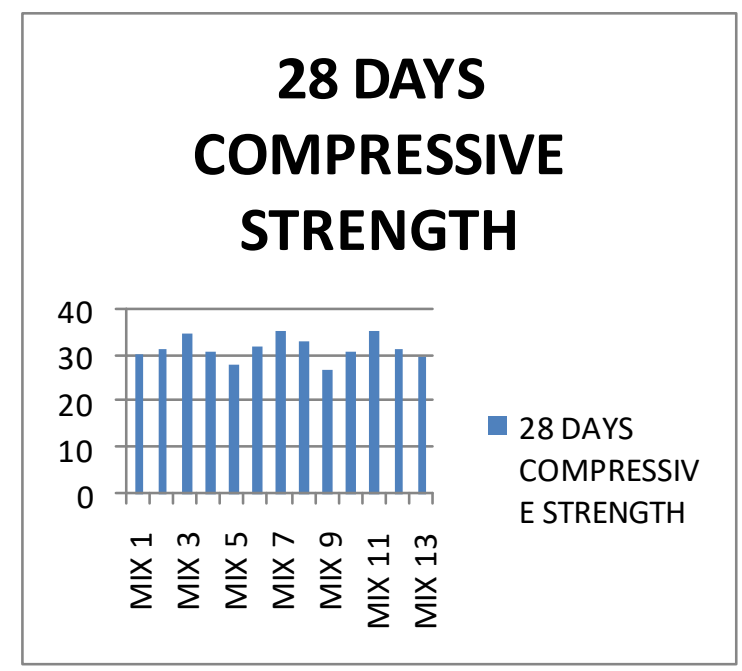

Fig.7.1 compressive strength of cubes for 28 days $\left(\mathrm{N} / \mathrm{mm}^{2}\right)$

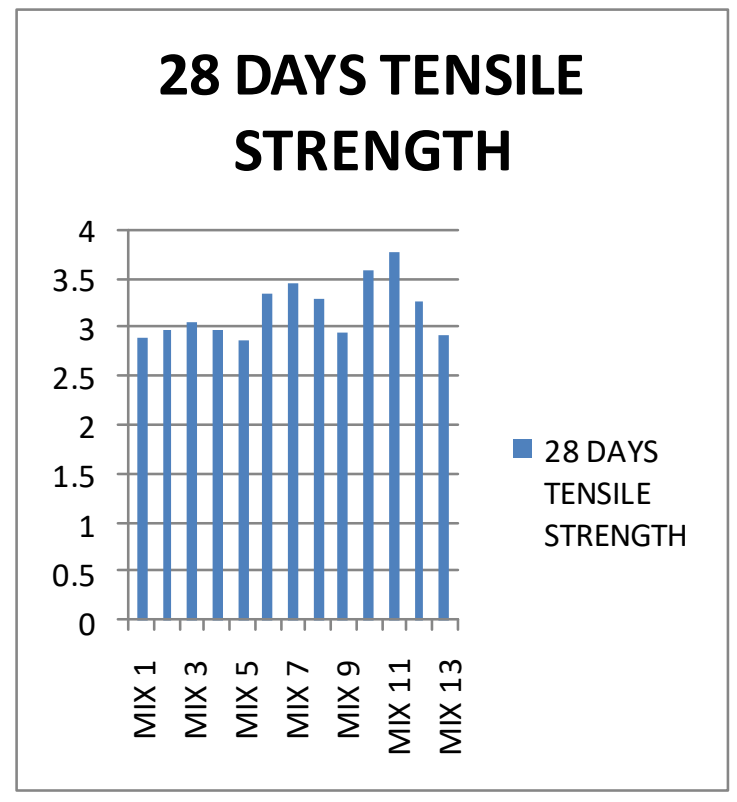

Fig.7.2 Tensile strength $\left(\mathrm{N} / \mathrm{mm}^{2}\right)$
Victor ajileye faseyemi (8) investigated compressive strength traits by replacing cement with FA and MS in self compacting concrete. SCC helps to settle the concrete without any external help or vibrations. He concluded that cement replacement up to $10 \% \mathrm{MS}+30 \% \mathrm{FA}$ when compared to normal concrete (control) decrease in compressive strength is recorded whereas combination of $2 \% \mathrm{~ms}+10 \% \mathrm{FA}$ when compared to control concrete increase in compressive strength is observed. So the best proportion that can be concluded for C50 grade in $3,7,28$ and 56 days is $2 \% \mathrm{MS}$ and $10 \% \mathrm{FA}$.

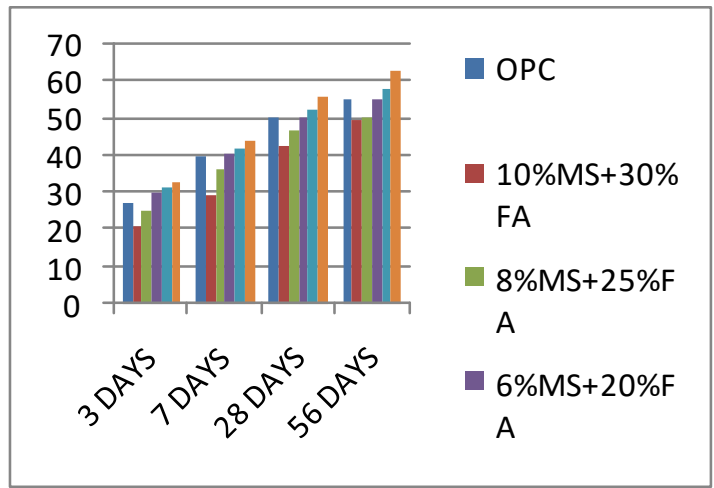

Fig.8.1 compressive strength of MS and FA levels of SSC (Mpa)

Ankit Kumar(9) inspected the use of MS individually and with combinations of FA and MS both in two stages in which he concluded that the strength of high performance concrete can be increased by replacing the cement with MS only. In the second stage cement is kept fixed at $90 \%$ and is replaced by FA and MS for curing period of 7 and 28 days. Maximum compressive strength increased by $1.43 \%$ after 7 days and $4.42 \%$ after 28 days at $10 \%$ replacement of cement with silica fume . however when both silica fume and FA in different percentage is replaced by keeping cement constant at $90 \%$ compressive strength continuously decreases after $2 \% \mathrm{FA}$ and $8 \% \mathrm{SF}$. Maximum flexural strength increased by $1.79 \%$ after 28 days at $10 \%$ replacement of cement with silica fume but when used in a combination of both by cement kept fixed at $90 \%$ continuous decrease in strength is recorded. Maximum split tensile strength is $3.83 \%$ when OPC is replaced by $10 \%$ of MS only after 28 days curing period. When cement is kept fixed at $90 \%$ continuous decrease in strength is recorded after $2 \% \mathrm{FA}$ and $8 \%$ SF. Hence according to his study replacement with silica fume enhances environment friendly deduction in cost and also increase in strength.

Alok Kumar (10) concluded that replacement of cement to an extent with FA and MS for M30 grade of concrete maximum compressive strength obtained is $43.1 \mathrm{~N} / \mathrm{mm}^{2}$ at replacement level of $7.5 \%$ by 
weight of MS and $20 \%$ by weight of FA. Maximum flexural strength obtained is $6.47 \mathrm{~N} / \mathrm{mm}^{2}$ at replacement level of $7.5 \%$ SF with $20 \%$ FA by weight of cement. Maximum split tensile strength obtained is $2.573 \mathrm{~N} / \mathrm{mm}^{2}$ at replacement level of $7.5 \%$ of SF with $20 \%$ of FA. From the experiment he also concluded that with use of both these materials environment problems along with cement conservation can be done.

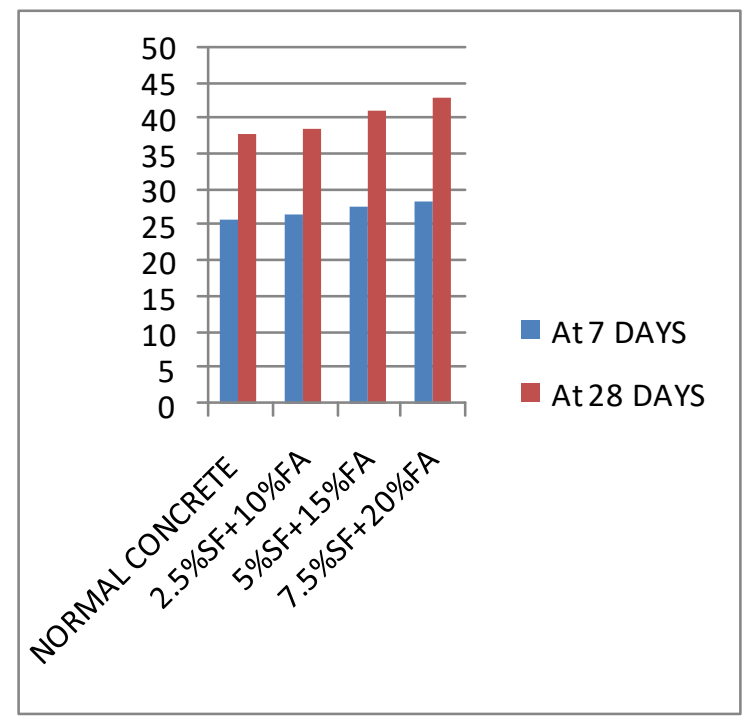

Fig.10.1 (compressive strength $\mathrm{N} / \mathrm{mm}^{2}$ )

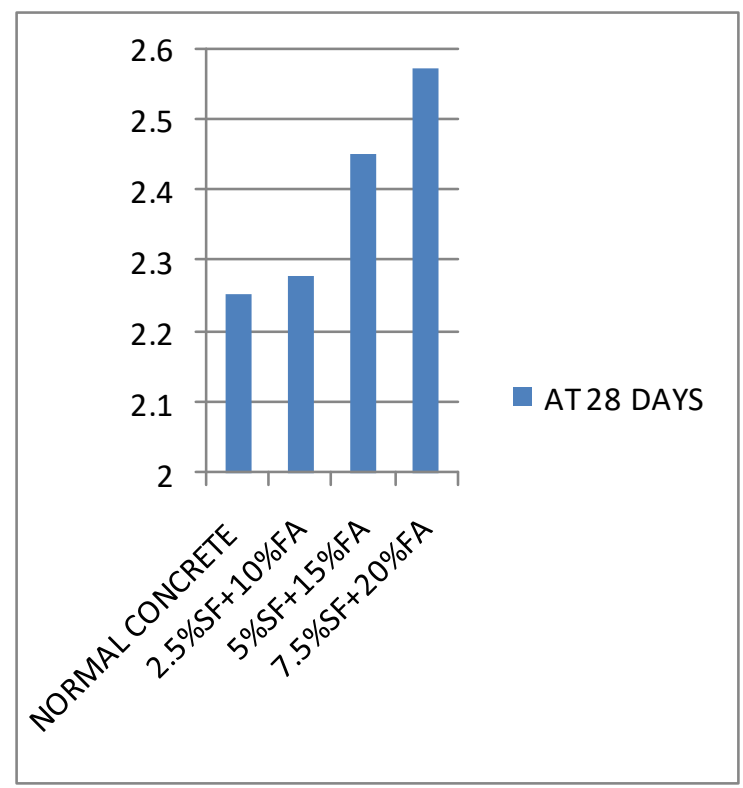

Fig.10.2 tensile strength $\left(\mathrm{N} / \mathrm{mm}^{2}\right)$

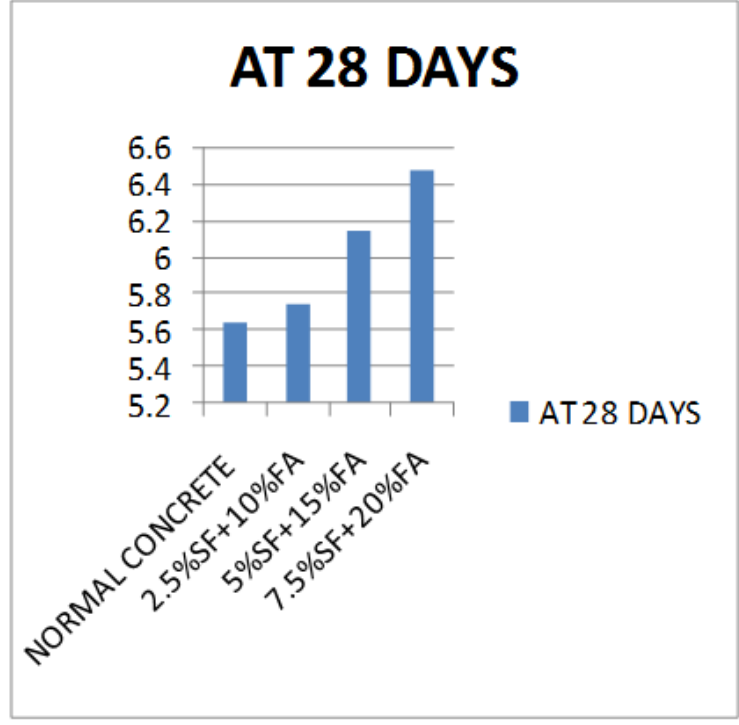

Fig.10.3 flexural strength $\left(\mathrm{N} / \mathrm{mm}^{2}\right)$

\section{CONCLUSION}

- FA and MS both are very fine in size in comparison with cement particles. Average diameter of these pozzolanic materials is smaller than cement. Due to its tiny size it is capable of filling small voids spaces present in concrete when it is in its fresh state. Due to this action it forms a strong bond and strength is increased.

- When dosage of MS is increased urge of water increases.

- In maximum cases replacement of cement up to $15 \%$ cause increase than other proportions.

- Use of both these materials can help in reduction of environmental problems, industrial doping and gainful construction.

\section{REFERENCES}

[1] https://www.ibef.org/industry/cement-india.aspx

[2] http://www.projectsmonitor.com/specialreports/indias-cement-demand-projected-toreach-600-mtpa-by-2025/

[3] Environmental impacts of cement production, Ing. Miroslav Stajanča, doc. RNDr. Adriana Eštokova, PhD Technical University of Košice, 296-302

[4] Verma ajay, Effect of Micro Silica on the strength of concrete with ordinary Portland cement, Research Journal of engineering sciences, 1(3), 2012, 1-4

[5] H S Jadhav and R R Chavarekar, role of Fly Ash and Micro silica (silica fume) on compressive strength characteristics of high performance concrete, International journal of structural and civil engineering research (IJSCER),2(1), 2013, 33-39

[6] Magudeaswaran P,and Eswaramoorthi P, Experimental investigations of mechanical properties on MS (Silica fume) and Fly Ash as 
partial cement replacement of high performance concrete, IOSR Journal of mechanical and civil engineering (IOSR-MCE), 6(4), 2013, 57-63

[7] Mudassir Hussain pandit, High density concrete using Fly Ash, Micro Silica and recycled aggregate- An Experimental study, International journal of engineering trends and technology(IJETT), 10(1), 2014, 29-33

[8] Victor Ajileye Faseyemi, Investigation into The use of Microsilica and Fly Ash in Self Compacting Concrete, International Journal of recent research and applied studies (IJRRAS), 24(2), 2015, 67-74

[9] Ankit Kumar, Effect of Silica Fume and Fly Ash as partial replacement of cement on strength of concrete, International Journal of innovative research in science, engineering and technology (IJIIRSCET), 5(10), 2016, 18618-18624

[10] Alok Kumar, Research Paper on Partial Replacement of Cement in M-30 Concrete from Silica Fume and fly ash, SSRG International Journal of Civil Engineering(SSRG-IJCE), 3(5), 2016, 40-45 